\title{
Maxillary Sinusitis
}

National Cancer Institute

\section{Source}

National Cancer Institute. Maxillary Sinusitis. NCI Thesaurus. Code C34809.

An acute or chronic inflammatory process affecting the mucous membrane of the maxillary sinus. 